\title{
Anti-cancer effect of engineered recombinant interleukin 18
}

\author{
Jirakrit Saetang ${ }^{1, A-D, F,}$, Pennapa Chonpathompikunlert ${ }^{2, B, C}$, Somporn Sretrirutchaj ${ }^{3, B, C}$, Niran Roongsawang ${ }^{4, A}$, Kanita Kayasut ${ }^{3, C}$, \\ Supayang Piyawan Voravuthikunchai ${ }^{5, B}$, Wanida Sukketsiri ${ }^{6, A}$, Varomyalin Tipmanee ${ }^{1, A}$, Surasak Sangkhathat ${ }^{1,7, A, D-F}$ \\ ${ }^{1}$ Department of Biomedical Sciences, Faculty of Medicine, Prince of Songkla University, Songkhla, Thailand \\ 2 Expert Center of Innovative Health Food, Thailand Institute of Scientific and Technological Research, Pathum Thani, Thailand \\ ${ }^{3}$ Department of Pathology, Faculty of Medicine, Prince of Songkla University, Songkhla, Thailand \\ ${ }^{4}$ Microbial Cell Factory Research Team, Biorefinery and Bioproduct Technology Research Group, National Center for Genetic Engineering and Biotechnology, \\ National Science and Technology Development Agency, Pathum Thani, Thailand \\ ${ }^{5}$ Department of Microbiology and Natural Product Research Center of Excellence, Faculty of Science, Prince of Songkla University, Songkhla, Thailand \\ ${ }^{6}$ Department of Pharmacology, Faculty of Science, Prince of Songkla University, Songkhla, Thailand \\ ${ }^{7}$ Department of Surgery, Faculty of Medicine, Prince of Songkla University, Songkhla, Thailand \\ A - research concept and design; $\mathrm{B}$ - collection and/or assembly of data; $\mathrm{C}$ - data analysis and interpretation; \\ $D$ - writing the article; $E$ - critical revision of the article; $F$ - final approval of the article
}

Address for correspondence

Varomyalin Tipmanee

E-mail: tvaromya@medicine.psu.ac.th

\section{Funding sources}

This research was supported by the government budget (grant No. SCl6101034M) and postdoctoral fellowship of Prince of Songkla University, Songkhla, Thailand

\section{Conflict of interest}

None declared

\section{Acknowledgements}

J.S. acknowledges the Central Research Laboratory, Faculty of Medicine, Prince of Songkla University, Songkhla, Thailand, for the use of all laboratory facilities. J.S. also would like to thank Mr. David Patterson of the International Affairs Office, Faculty of Medicine, Prince of Songkla University, for manuscript proofreading and language editing service.

Received on May 14, 2020

Reviewed on June 23, 2020

Accepted on August 11, 2020

Published online on 0ctober 8, 2020

Cite as

Saetang J, Chonpathompikunlert P, Sretrirutchai S, et al.

Anti-cancer effect of engineered recombinant interleukin 18 Adv Clin Exp Med. 2020;29(10):1135-1143.

doi:10.17219/acem/126298

DOI

10.17219/acem/126298

\section{Copyright}

Copyright by Author(s)

This is an article distributed under the terms of the

Creative Commons Attribution 3.0 Unported (CC BY 3.0)

(https://creativecommons.org/licenses/by/3.0/)

\begin{abstract}
Background. Interleukin 18 (IL-18) is an inflammatory cytokine belonging to the interleukin 1 (IL-1) superfamily, and is known for its role in anti-cancer activity by promoting type 1 immune response, and thus may be applied to cancer immunotherapy. Our previous report has showed 16 times higher activity of engineered E6K+T63A IL-18 than of native IL-18 in vitro. However, no data has been acquired for its anti-cancer effect in animal model.
\end{abstract}

Objectives. To investigate the anti-cancer effect of engineered E6K+T63A IL-18 as an immune stimulant in vivo.

Material and methods. Tumor-bearing mice were treated with native IL-18 or E6K or E6K+T63A IL-18 once a day for 10 days after the tumor reached the volume of $100 \mathrm{~mm}^{3}$. Tumor volume and the number of certain immune cell type in the tumor microenvironment were investigated in this study.

Results. The results showed that tumor progression in mice treated with E6K+T63A was slower than in mice treated with E6K and native IL-18. The volume of the tumor was also smaller and the lifespan longer in the E6K+T63A IL-18-treated mice. The proportions of type 1 helper T cell (Th1) and cytotoxic T lymphocyte (CTL) were significantly higher in mice treated with E6K+T63A IL-18.

Conclusions. These results suggest that our engineered IL-18 conferred strong anti-tumor immunity in the animal model.

Key words: Th1, in vivo, interleukin-18, CTL, anti-cancer immunity 


\section{Introduction}

Interleukin 18 (IL-18) is an inflammatory cytokine belonging to the interleukin 1 (IL-1) superfamily. Formerly, interleukin-18 was known as interferon $\gamma$ (IFN- $\gamma$ ) inducing factor due to its function in IFN- $\gamma$ enhancement. ${ }^{1}$ Interleukin 18 drives the polarization of $\mathrm{CD}^{+} \mathrm{T}$ cells toward the helper T cell type 1 (Th1) phenotype when co-stimulated with IL-12 or IL-15, which is identified through IFN- $\gamma$ production. ${ }^{2-4}$ Interleukin 18 can also polarize human natural killer (NK) cells to develop a distinct helper differentiation phenotype $\left(\mathrm{CD} 83^{+} \mathrm{CCR} 7^{+} \mathrm{CD} 25^{+}\right)$, which effectively produces IFN- $\gamma \cdot{ }^{5,6}$ Moreover, IL-18 can activate M1 macrophage and inhibit angiogenesis. ${ }^{7}$ Interleukin 18 has been studied as a tumor suppressor protein in animal models, and has been administered safely to patients in clinical trials. ${ }^{8-11}$ Various studies have shown that IL-18 can act as a tumor suppressor when the cytokine is administered through an intraperitoneal, ${ }^{12-14}$ intravenous, ${ }^{12}$ intratumoral, ${ }^{15}$ or peritumoral ${ }^{16}$ route.

Many studies have tried to combine the anti-tumor function of IL-18 with other tumor treatment methods, especially immunotherapy. Two studies trialed IL-18 in combination with adoptive dendritic cell (DC) transfer, which resulted in the enhancement of the cytotoxic efficacy of tumor specific cytotoxic T lymphocytes (CTLs) in vitro and recruited the mobilized DCs into the tumor bed in vivo. ${ }^{17,18}$ Moreover, IL-18-secreting chimeric antigen receptor $\mathrm{T}$ (CAR-T) cells have also demonstrated the augmentation of anti-tumor immunity in solid tumors. ${ }^{19,20}$ Using IL-18 as an adjuvant combination with other cytokines, such as interferon $\alpha$ (IFN- $\alpha$ ), IL-15, IL-12, and IL-2, can also promote productive dendritic cell $\mathrm{T}$ (DC-T) cell interactions, and promote the activation and proliferation of T cells in colorectal cancer patients. ${ }^{21}$ A human IL18-IL2 fusion protein has also been developed, and the resulting study ${ }^{8}$ showed that it could provoke the IFN- $\gamma$ production in peripheral blood mononuclear cells (PBMCs), and increase the production of IFN- $\gamma$ and the cytotoxicity of NK cells to a higher degree than when stimulated with only IL-18 or IL- 2 or a combination of both. ${ }^{8}$

In a previous study, we developed a type of engineered IL-18 with higher activity than the native protein. ${ }^{22}$ The modification using site-directed mutagenesis based on its receptor interaction and other previous reports. ${ }^{23-25}$ We named the modified protein E6K+T63A IL-18, and our study showed that E6K+T63A IL-18 exhibited higher IFN- $\gamma$ inducing activity from NK-92MI cells by a factor of 16 compared with native IL-18. ${ }^{22}$ Molecular dynamic (MD) simulation also indicated that the activity change of this engineered IL-18 came together with some kind of conformational changes at the binding sites of IL-18.

In this article, we demonstrate that in addition to the previous in vitro testing which found the higher IFN- $\gamma$ induction activity of E6K+T63A IL-18 from cell culture, it also promoted anti-tumor immunity in vivo through increasing the recruitment of Th1 and CTL cells in the tumor bed. This finding indicates the potential of engineered IL-18 as either a sole candidate or with other regimens for cancer immunotherapy in the future.

\section{Material and methods}

\section{Cloning and mutagenesis}

pPICZ $\alpha-I L 18 \mathrm{WT}, \mathrm{pPICZ} \alpha-\mathrm{IL} 18 \mathrm{E} 6 \mathrm{~K}$ and $\mathrm{pPICZ} \alpha-$ IL18E6K+T63A constructions have been described extensively in our previous study. ${ }^{22}$ In brief, the IL-18 open reading frame (ORF) was cloned from an RNA sample. We first introduced this ORF to the pTZ57R/T cloning vector (Thermo Fisher Scientific, Waltham, USA) and then subcloned the ORF into the yeast expression vector pPICZ $\alpha \mathrm{A}$ (Invitrogen, Carlsbad, USA) at the EcoRI and XbaI sites, resulting in the recombinant plasmid pPICZ $\alpha$-IL18WT. The mutagenesis, using $\mathrm{pPICZ} \alpha$-IL18WT as a template, was carried out to generate $\mathrm{PPICZ} \alpha$-IL18E6K for the E6K+T63A IL-18. Platinum Pfx DNA polymerase (Invitrogen) was used to perform all mutagenesis processes. The purified PCR fragments were digested with DpnI (Thermo Fisher Scientific) to remove the plasmid template, and transformed into Escherichia coli DH5 $\alpha$.

\section{Protein production and purification}

Our protein production method was also described in a previous report. ${ }^{22}$ Plasmid pPICZ $\alpha$-IL18WT and other mutagenized plasmids were linearized with $\mathrm{SacI}$ (Thermo Fisher Scientific) enzyme, electroporated to Pichia pastoris, and then selected on yeast extract peptone dextrose (YPD) medium containing $100 \mu \mathrm{g} / \mathrm{mL}$ of Zeocin (Invitrogen). The positive clones were cultured on YPD, buffered glycerol complex medium (BMGY) and buffered methanolcomplex medium (BMMY) for inoculum preparation, yeast mass production and protein expression, respectively. For protein expression, $2.0 \%$ methanol was used as an inducer. The cell culture was cultivated at $30^{\circ} \mathrm{C}, 250 \mathrm{rpm}$, for $48 \mathrm{~h}$. The volume of the culture was maintained at $10-30 \%$ of the total flask volume to ensure sufficient aeration. Methanol was added every $24 \mathrm{~h}$ to maintain the induction at $2 \%$ methanol concentration. The collected supernatant confirmed recombinant IL-18 existence using SDS-PAGE and western blotting.

The secreted IL-18 protein was then purified using HisTrap HP column (GE Healthcare, Chicago, USA) according to the manufacturer's protocol. The $\mathrm{pH} 7.4$ binding buffer contained $20 \mathrm{mM}$ sodium phosphate, $0.5 \mathrm{M} \mathrm{NaCl}$ and $20 \mathrm{mM}$ imidazole. The elution buffer followed the binding buffer formula but $400 \mathrm{mM}$ imidazole was used instead. The recombinant protein was then concentrated using an Amicon Ultra4 centrifugal filter unit (Merck Millipore, Burlington, USA) and diluted in phosphate-buffered saline 
(PBS). The protein concentration was measured using Bradford assay and bovine serum albumin (BSA) was used as a standard. Finally, the purified protein was submitted to Proteomics International Pty Ltd. (Perth, Australia) for LC-MS/MS analysis.

\section{Cell line, animal model and assessment of treatment effect}

Mouse CT26-WT colon cancer cells (American Type Culture Collection (ATCC); CRL-2638) were obtained from ATCC (Manassas, USA). CT26-WT is an N-nitro-Nmethylurethane-induced BALB/c murine colon carcinoma cell line. The cell line in our study was grown in RPMI1640 medium supplemented with $10 \%(\mathrm{v} / \mathrm{v})$ fetal bovine serum (FBS) and $2 \mathrm{mM} \mathrm{L}$-glutamine at $37^{\circ} \mathrm{C}$ in $5 \% \mathrm{CO}_{2}$.

Ninty-four male seven- to nine-week-old BALB/c mice (27-30 g body weight) were obtained from the National Laboratory Animal Center (Nakhon Pathom, Thailand) and maintained in the Southern Laboratory Animal Facility, Faculty of Science, Prince of Songkla University, Songkhla, Thailand. The maintenance conditions were a temperature of $22 \pm 3^{\circ} \mathrm{C}$, relative humidity of $55 \pm 10 \%$, free access to clean food and water, and 12-hour lighting. All animal procedures were performed following guidelines and regulations approved by the Ethics Committee of Prince of Songkla University (animal experimentation application Ref. 15-2017). During the logarithmic growth phase, CT26-WT cells were harvested and screened with trypan blue to allow the preparation of single-cell suspensions with $90 \%$ viability before inoculation. Each group of mice was injected subcutaneously with $2 \times 10^{6}$ CT26-WT cancer cells/100 $\mu \mathrm{L}$ of PBS in the left hind flank. Survival times and tumor volumes were monitored after inoculation. The CT26 mice were randomized into 4 groups (9 mice/group) as follows: group A (vehicle group); group B (IL-18WT group); group C (IL-18E6K group); and group D (IL-18E6K+T63A).

The $1^{\text {st }}$ day of treatment was defined as day 0 . The mice were continuously observed for 100 days before sacrifice. Kaplan-Meier survival analysis was performed using death as the definition of failure in censoring. Group A mice received $\mathrm{PBS}$ solution injection to serve as vehicle control. Groups B, C and D mice received $50 \mu \mathrm{g} / \mathrm{kg}$ of IL-18WT, IL-18E6K and IL-18 E6K+T63A, respectively. The intratumoral injection was performed once a day for 10 consecutive days. Tumor volumes were measured with caliper every day. The tumor volume of $2000 \mathrm{~mm}^{3}$ or tumor abnormal status (ulcerated, infected and/or $>30 \%$ body weight loss) indicated the sacrifice notification. No sign of these endpoints in the animal was detected until the end of the experiment. After 10 days of treatment, the mice were sacrificed. The tumor was collected for flow cytometry and weight and size analysis.

Another set of mice has been used for a survival study. Tumor-bearing mice were divided into 4 groups (12 mice/ group). The mice were treated with different forms of IL-18 or PBS for 10 days. The animal survival rate was evaluated for 100 days. The animal health and behavior were monitored 4 times/week.

\section{Leukocyte isolation}

Inhalation of $4 \%$ isoflurane was applied for deep anesthetization and blood samples were extracted. Later, the tumors were removed and kept in complete RPMI media during transportation from the animal facility to the laboratory. The mice were intracardially perfused with saline buffer, and euthanasia was performed under anesthesia by exsanguination. The euthanasia status was confirmed with cervical dislocation.

The tumors were dissected into small fragments and incubated in completed RPMI media at $37^{\circ} \mathrm{C}$ for $45 \mathrm{~min}$ with agitation. RPMI media contained $1 \mathrm{mg} / \mathrm{mL}$ type IV collagenase (Sigma-Aldrich, St. Louis, USA), $0.1 \mathrm{mg} / \mathrm{mL}$ hyaluronidase (Sigma-Aldrich) and $20 \mathrm{U} / \mathrm{mL}$ DNase I (Sigma-Aldrich). The cell suspension was then filtered through a $70 \mu \mathrm{m}$ cell strainer on a $50 \mathrm{~mL}$ tube, and followed by rinsing with $5 \mathrm{~mL}$ RPMI medium. The single cell suspension was centrifuged at $300 \times \mathrm{g}$ for $10 \mathrm{~min}$ to get the cell pellet. The cell pellet was washed using complete RPMI medium and incubated with $5 \mathrm{~mL}$ RBC lysis buffer for $5 \mathrm{~min}$. The cells were then washed again and resuspended in $15 \mathrm{~mL}$ of $40 \%$ Percoll (GE Healthcare) in RPMI. The suspension was under-laid on $15 \mathrm{~mL} 80 \%$ Percoll and centrifuged for $25 \mathrm{~min}$ at $400 \times \mathrm{g}$ with the lowest descending and ascending rates. The leukocytes were collected from the interphase between the 2 concentrations.

\section{Flow cytometry}

The isolated leukocytes were counted using a hemacytometer, adjusted at $2 \times 10^{6}$ cells $/ \mathrm{mL}$ and incubated in complete RPMI medium containing a cell activation cocktail (BioLegend, San Diego, USA). The cocktail included $20 \mathrm{ng} / \mathrm{mL}$ of phorbol 12-myristate-13-acetate (PMA), $1 \mu \mathrm{g} / \mathrm{mL}$ of ionomycin and $5 \mu \mathrm{g} / \mathrm{mL}$ of brefeldin A for $4 \mathrm{~h}$ at $37^{\circ} \mathrm{C}$ in a $\mathrm{CO}_{2}$ incubator. The cells were washed with a cell-staining buffer (BioLegend) before adjusting to $2 \times 10^{7}$ cells $/ \mathrm{mL}$. The cells were then incubated with $10 \mathrm{ng} / \mu \mathrm{L}$ TruStain $\mathrm{fcX}^{\mathrm{TM}}$ (BioLegend) for $10 \mathrm{~min}$ on ice. Cell surface antibodies (anti-mouse CD4 and anti-mouse CD8a) were added, as shown in Table 1, and the solution was incubated on ice for $20 \mathrm{~min}$ in a dark environment.

The cells were washed and fixed with $\times 5$ volume of fixation buffer (BioLegend) for $20 \mathrm{~min}$ at room temperature in a dark environment. The cells were then washed with cell staining buffer and twice in permeabilization wash buffer (BioLegend) before being stained with fluorescence-conjugated antibodies against intracellular cytokines (anti-mouse IFN- $\gamma$ and anti-mouse IL-4; Table 1) for $20 \mathrm{~min}$ at room temperature in a dark environment. 
Table 1. Antibodies used in this study

\begin{tabular}{|c|c|c|c|}
\hline Antibody & Provider & Clone & Volume used $[\mu \mathrm{L}]$ \\
\hline \multicolumn{4}{|c|}{ Cell surface markers } \\
\hline FITC Rat anti-mouse CD4 & BioLegend & GK1.5 & 0.5 \\
\hline FITC Rat lgG2b, k isotype & BioLegend & RTK4530 & 0.5 \\
\hline FITC Rat anti-mouse CD8a & BioLegend & $53-6.7$ & 2 \\
\hline FITC Rat lgG2a, k isotype & BioLegend & RTK2758 & 2 \\
\hline \multicolumn{4}{|c|}{ Intracellular cytokine markers } \\
\hline PE Rat anti-mouse IL-4 & BioLegend & $11 \mathrm{~B} 11$ & 1.25 \\
\hline PE Rat IgG1, $\mathrm{k}$ isotype & BioLegend & RTK2071 & 1.25 \\
\hline APC Rat anti-mouse IFN- $\gamma$ & BioLegend & XMG1.2 & 4 \\
\hline APC Rat lgG1, k isotype & BioLegend & RTK2071 & 4 \\
\hline \multicolumn{4}{|c|}{ Fc block antibody } \\
\hline Anti-mouse CD16/32 & BioLegend & 93 & 2 \\
\hline
\end{tabular}

The double-stained cells were then washed twice with permeabilization wash buffer and resuspended in cell staining buffer before flow cytometry analysis using the BD FACSCalibur $^{\mathrm{TM}}$ platform (BD Biosciences, San Jose, USA) and analyzed using Kaluza analysis flow cytometry software (Beckman Coulter, Brea, USA).

\section{Statistical analysis}

All data are presented as mean \pm standard deviation (SD). Kaplan-Meier method was applied to analyze survival data using the logrank test. Multiple conditions were compared using a parametric one-way analysis of variance (ANOVA), followed by Tukey's post hoc tests. All analyses were performed using SPSS v. 24.0 (IBM Corp., Armonk, USA). The p-value $<0.05$ justified statistical significance.

\section{Results}

\section{Engineered IL-18 increased the lifespan of tumor-bearing mice}

In our previous study, we developed 3 types of engineered IL-18, namely E6K, T63A and E6K+T63A IL-18. All showed higher ability to induce IFN- $\gamma$ production from NK-92MI cells than a native IL-18 with the rates of 9.3, 3.9 and 16.4 times higher at a concentration of $200 \mathrm{ng} / \mathrm{mL} .^{22}$ In the current study, we have selected E6K and E6K+T63A IL-18 to evaluate the anti-tumor effects of recombinant IL-18 in an animal model since these are the best 2 forms. BALC/c mice were injected with CT26-WT cell line subcutaneously to create tumor-bearing mice. The mice were separated randomly into 4 different treatment regimens as follows: native IL-18, E6K, E6K+T63A, and vehicle. Therapy was instituted according to the schema presented in Fig. 1A.

When the tumors reached $100 \mathrm{~mm}^{3}$, the mice were injected with one of the recombinant IL-18 types once a day for
A

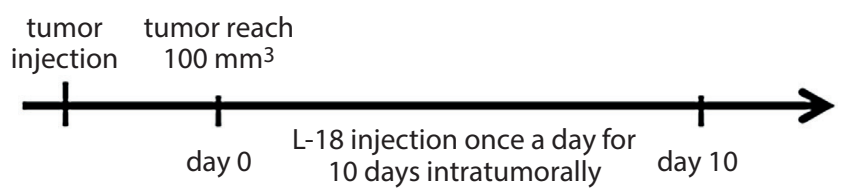

B

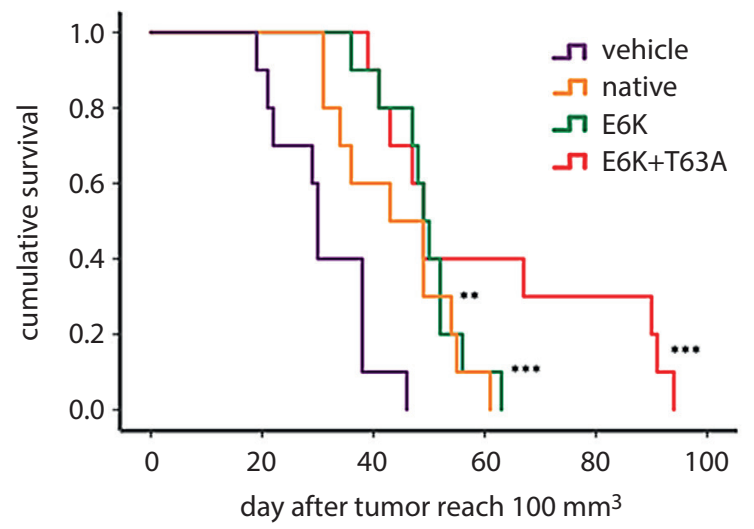

Fig. 1. Mice treated with recombinant IL-18 showed improved survival rates from a colon tumor model challenge. A. The treatment schematic. B. Kaplan-Meier analyses of overall survival in each group of mice $(n=10)$ $\left.{ }^{*} \mathrm{p}<0.05 ;{ }^{* *} \mathrm{p}<0.01 ;{ }^{* * *} \mathrm{p}<0.001\right)$

10 days intratumorally. After receiving $50 \mu \mathrm{g} / \mathrm{kg}$ of recombinant protein, the average survival times were $31.1 \pm 2.7$ (mean $+\mathrm{SD}$ ) days in the vehicle group, $44.3 \pm 3.4$ days in the native IL-18-treated group, $49.4 \pm 2.3$ days in the E6K group, and $61.0 \pm 7.1$ days in the double-mutation treatment group (Table 2). This data indicates that the long-term survival of the mice was related to the type of recombinant IL-18 received, since the mice treated with all types of recombinant IL-18 ( $\mathrm{n}=10)$ survived significantly longer than the vehicle group $(\mathrm{n}=10$ ) (Fig. $1 \mathrm{~B}$ ) with the $\mathrm{p}$-values $<0.008$ for native IL-18 and $<0.0001$ for both E6K and E6K+T63A, suggesting the in vivo efficacy of recombinant IL-18. However, the differences between the 3 recombinant IL-18 
Table 2. Statistical analysis of survival rate of each group of mice treated with different IL-18 regimens

\begin{tabular}{|c|c|c|c|c|c|c|c|c|c|c|}
\hline \multirow{3}{*}{ Intervention } & \multicolumn{2}{|c|}{ Mean survival time [days] } & \multicolumn{8}{|c|}{ Pairwise comparisons (Mantel-Cox test) } \\
\hline & \multirow{2}{*}{ estimate } & \multirow{2}{*}{ SE } & \multicolumn{2}{|c|}{$\mathrm{E} 6 \mathrm{~K}+\mathrm{T} 63 \mathrm{~A}$} & \multicolumn{2}{|c|}{ E6K } & \multicolumn{2}{|c|}{ native } & \multicolumn{2}{|c|}{ vehicle } \\
\hline & & & $x^{2}$ & $p$-value & $x^{2}$ & $p$-value & $x^{2}$ & p-value & $x^{2}$ & $p$-value \\
\hline Vehicle & 31.100 & 2.795 & 16.195 & $0.000^{*}$ & 15.312 & $0.000^{*}$ & 7.002 & 0.008 & - & - \\
\hline Native & 44.300 & 3.435 & 3.182 & 0.074 & 0.570 & 0.450 & - & - & 7.002 & 0.008 \\
\hline E6K & 49.400 & 2.358 & 1.510 & 0.219 & - & - & 0.570 & 0.450 & 15.312 & $0.000^{*}$ \\
\hline $\mathrm{E} 6 \mathrm{~K}+\mathrm{T} 63 \mathrm{~A}$ & 61.000 & 7.116 & - & - & 1.510 & 0.219 & 3.182 & 0.074 & 16.195 & $0.000^{*}$ \\
\hline
\end{tabular}

${ }^{*} \mathrm{p}<0.0001 ; \mathrm{SE}-$ standard error.

groups were not significant (Table 2), although the mice treated with E6K+T63A showed the longest survival time (61 \pm 7 days).

\section{Engineered IL-18 slowed tumor progression in vivo}

In addition to the survival analysis of each of the regimen groups, we also investigated whether tumor growth was affected by the different types of IL-18. An experimental model was generated as described earlier. The results showed that the double-mutation $(\mathrm{E} 6 \mathrm{~K}+\mathrm{T} 63 \mathrm{~A})$ and E6K groups had significantly lower tumor volumes when compared to the vehicle group ( $\mathrm{p}<0.0001$ at day 10 of treatment) and native protein-treated groups ( $\mathrm{p}<0.0001$ and $\mathrm{p}<0.05$, respectively) (Fig. 2A,B). Tumor growth in mice receiving intratumoral administration of native IL-18 was also slower than in the vehicle group with the p-value of 0.019 (Fig. 2A,B). Indeed, E6K IL-18 induced about 50\% reduction in tumor volume, and the combination of $\mathrm{E} 6 \mathrm{~K}$ with T63A had a high inhibitory effect (around 70\% reduction in tumor volume) (Fig. 2B).

The tumor weights were also measured after 10 days of treatment. As shown in Fig. 2C, the tumor weights in mice treated with recombinant IL-18 were considerably lower than in the vehicle mice. The tumors were also significantly smaller in the tumor-bearing mice injected with all types of recombinant IL-18 (Fig. 2C,D). The average tumor weight from the E6K+T63A-treated group was 5 and 3.6 times lower than the tumors from the vehicle
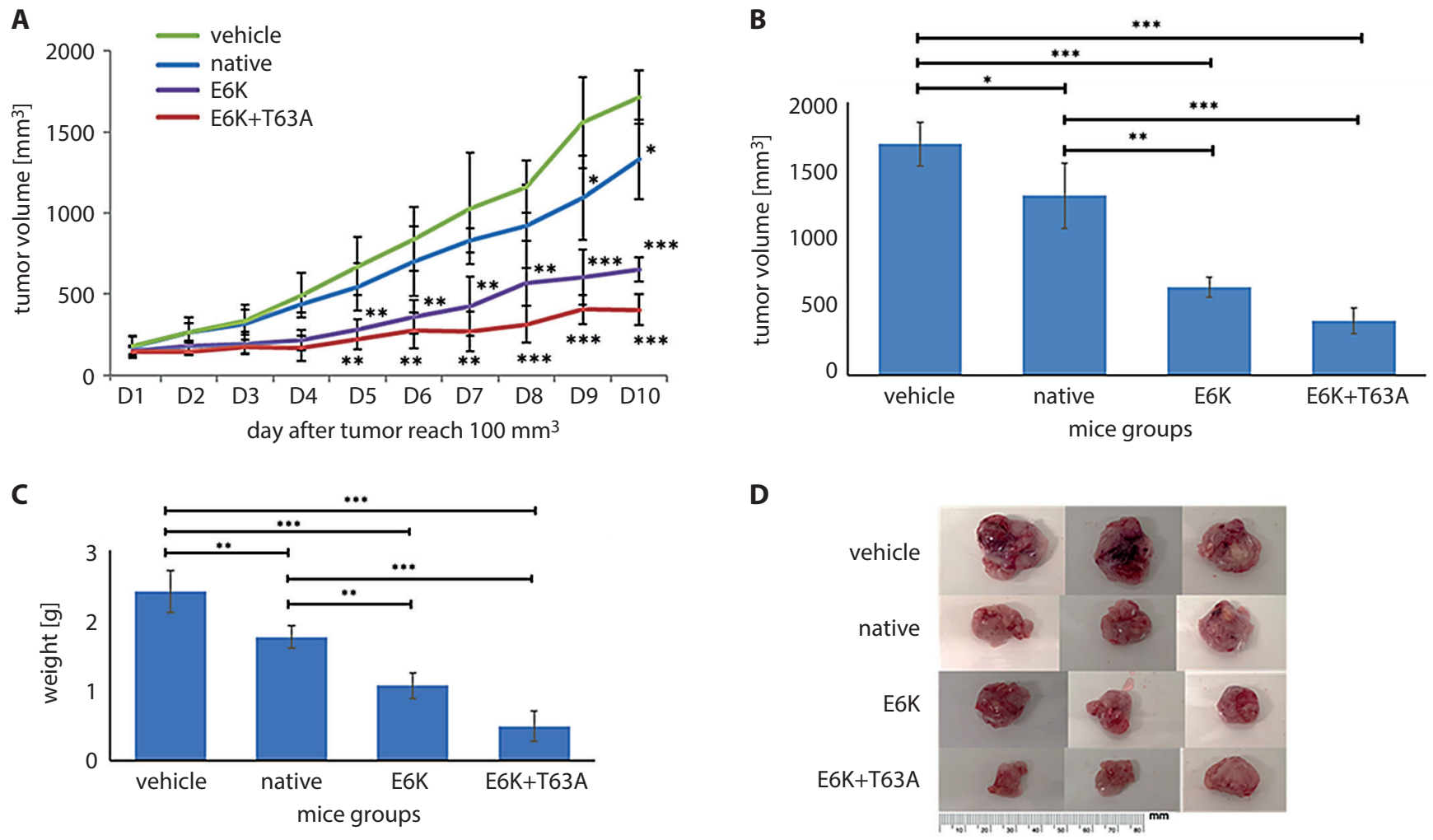

Fig. 2. Intratumoral recombinant IL-18 injection suppressed tumor growth in vivo. A. Groups of 10 tumor-bearing mice were challenged with each type of recombinant IL-8. Tumor size was measured every day starting on day 1 after IL-18 treatment. B-D. The tumor volumes and weights were measured. The image represents tumor growth at 10 days after IL-18 treatment. Results shown as means \pm SD of 5 animals/group; values having different signs are significant different $\left({ }^{*} p<0.05,{ }^{* *} p<0.01,{ }^{* * *} p<0.001\right)$ 
A

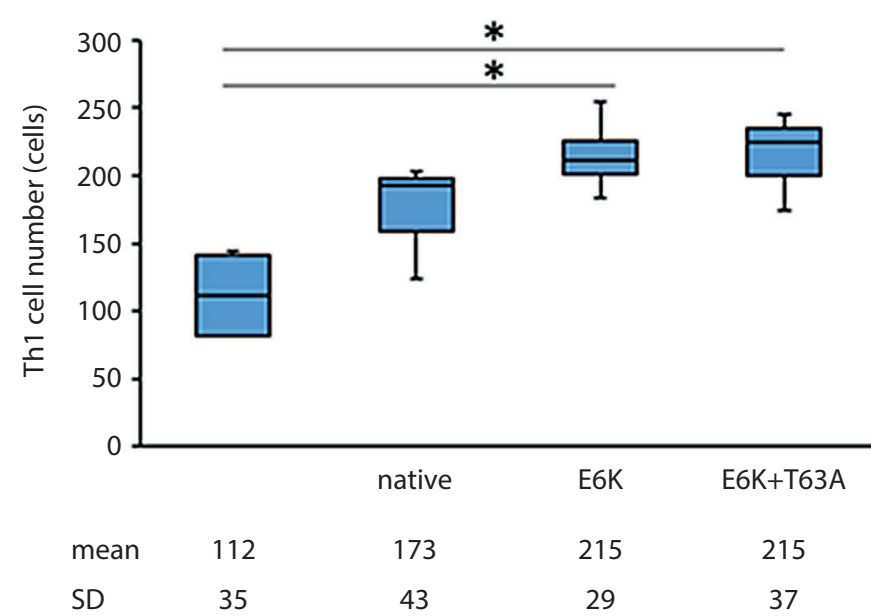

C

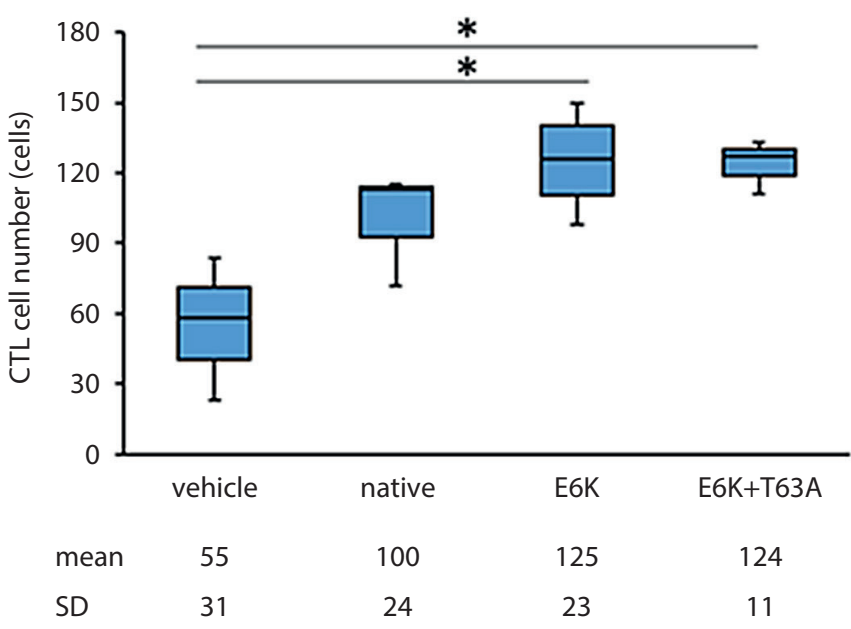

and native IL-18-treated groups, respectively. This quantification of the tumor size and weight confirmed that E6K+T63A IL-18 significantly reduced the xenograft tumor volume (Fig. 2A,B) and tumor weight (Fig. 2C,D).

\section{Engineered IL-18 increased the number of Th1 and CTL cells in the tumor bed}

We investigated the number of different types of $\mathrm{T}$ cells to determine whether our recombinant IL-18 indeed induced $T$ cell activity in the context of anti-tumor immunity. The phenotype of lymphocytes in tumors of the CT26WT-bearing mice after recombinant IL-18 treatment was examined. After treatment with each regimen, the tumor masses were collected and the mononuclear cells were then isolated using Percoll gradient centrifugation. All cells were subjected to flow cytometry after anti-body staining against CD4, CD8, IL-4, and IFN- $\gamma$. The Th1, Th2 and CTL cells were identified as CD4 ${ }^{+} \mathrm{IFN}-\gamma^{+}, \mathrm{CD} 4^{+} \mathrm{IL}-4^{+}$and $\mathrm{CD} 8^{+} \mathrm{IFN}-\gamma^{+}$, respectively, using flow cytometry and gating
B

Th2 cells

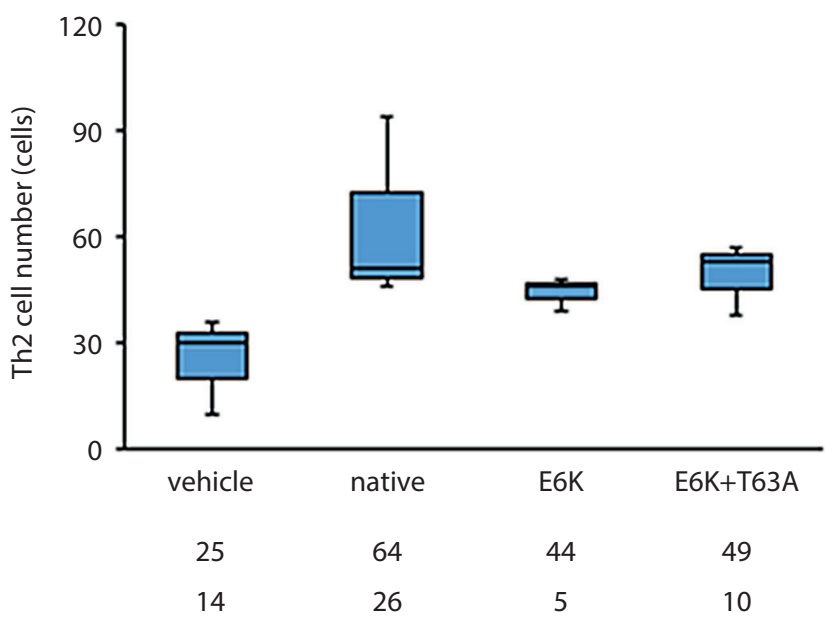

Fig. 3. The comparison of immune cells in the tumor microenvironment in each experiment groups to vehicle. A. Th1 cells. B. Th2 cells. C. CTL. Results shown as means \pm SD of 3-4 animals/group; values having different signs are significant different $\left({ }^{*} p<0.05\right)$

on viable cells. The results as presented in Fig. 3 showed that the numbers of Th1 and CTL significantly increased in the tumor masses of the E6K- and E6K+T63A IL-18treated groups compared to the vehicle group $(\mathrm{p}<0.05)$ (Fig. 3,4). However, there was no difference in the numbers of Th2 cells from the mice treated with all types of IL-18 as compared to the vehicle group (Fig. 3B,4B). These data demonstrate directly that E6K+T63A IL-18 induced the strongest functional Th1 and CTL response, correlating with the in vivo tumor therapy data.

\section{Discussion}

Interleukin 18 was widely reported for its potential as an anti-cancer agent. Application of IL-18 is thought to enhance the stimulation of NK cells and cytotoxic $\mathrm{T}$ lymphocytes, the cancer cell growth and spread inhibition, and the expression of Fas-ligand in immune cells. ${ }^{26-30}$ Moreover, these anti-tumor functions of IL-18 are mainly 

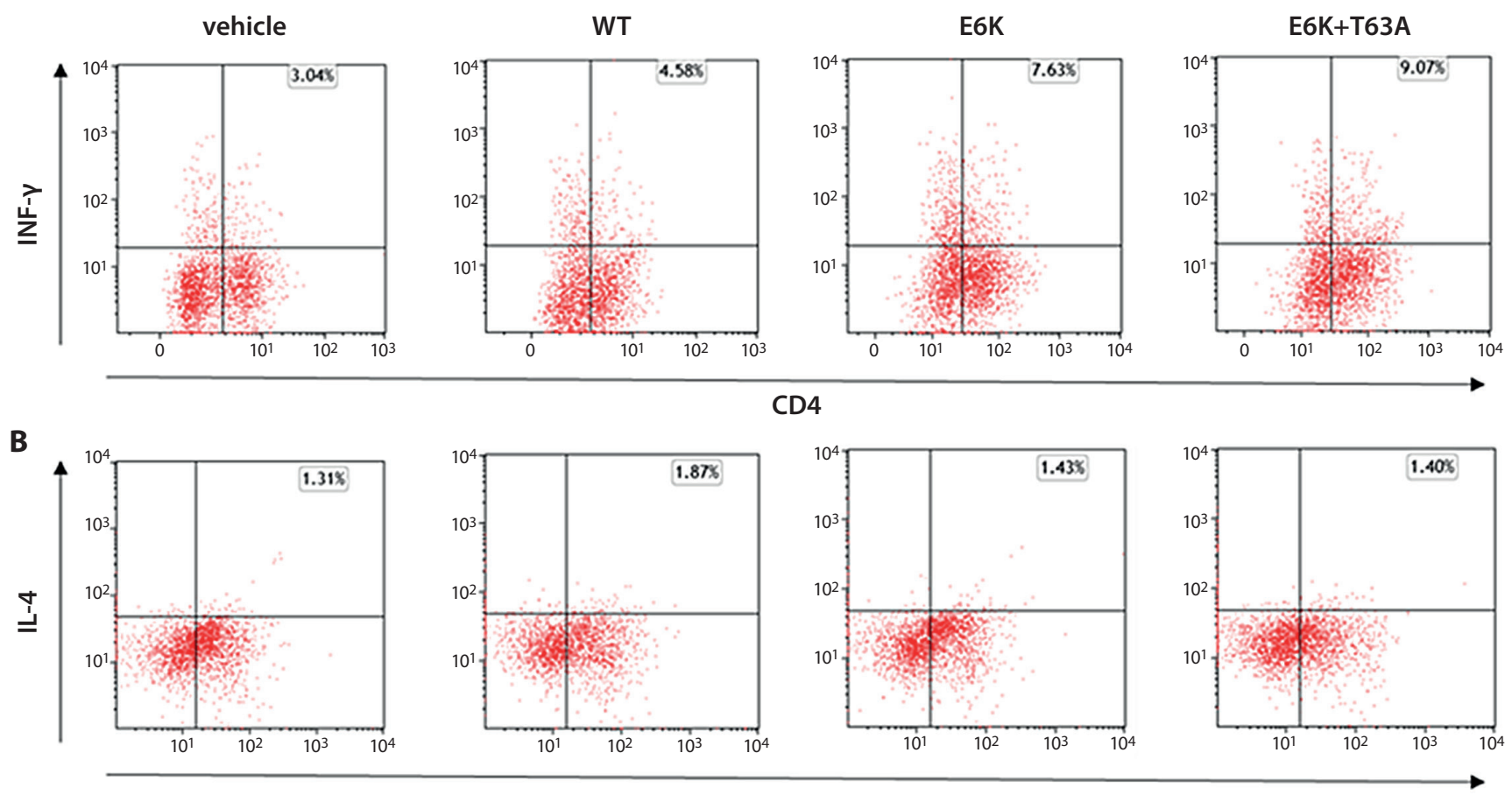

C
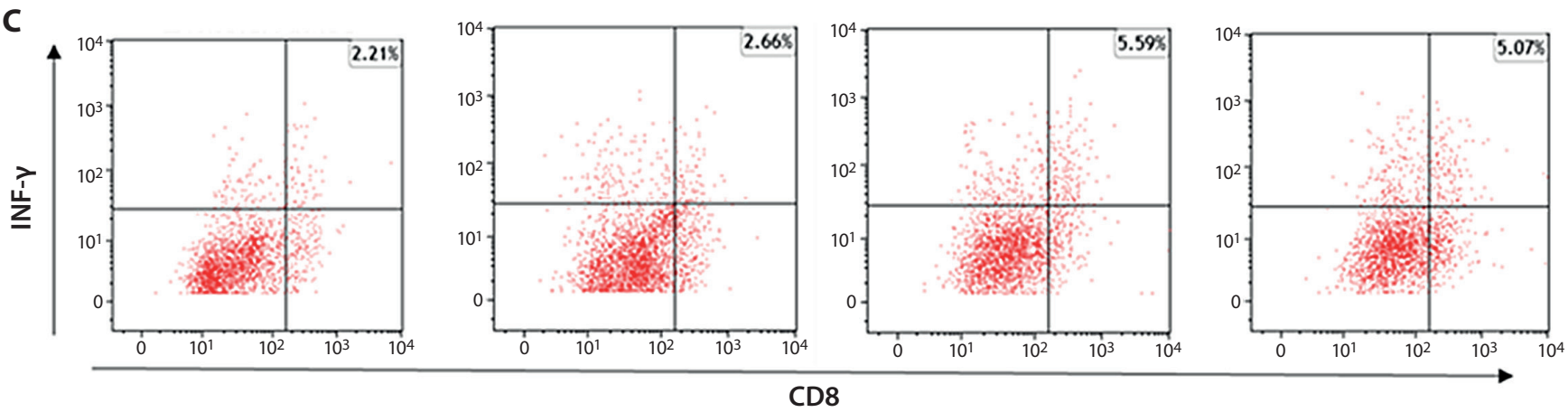

Fig. 4. Representative flow cytometry gating plots showing the percentage of tumor infiltrating. Th1 (A), Th2 (B) and CTL (C) cells from mice treated with different types of recombinant IL-18 or vehicle

mediated through IFN- $\gamma,{ }^{31}$ the downstream molecule after IL-18 activation. ${ }^{1}$ In our previous experiment, we demonstrated that altering amino acids as E6K+T63A improved IL-18 activity. ${ }^{22}$ The proteins were also produced by the yeast system that gave us a low cost and no need for the refolding steps presented in the $E$. coli system. Moreover, some earlier studies have suggested that the route of administration of IL-18 also plays an important role in the therapeutic effects of a cytokine, since 1 study found that IL-18 only slowed tumor progression when administered directly into the tumor mass or if the cytokine was secreted by tumor cells, indicating that the tumor microenvironment can be an effective target for tumor treatment. ${ }^{31}$ This was also confirmed by several other studies in which an intratumoral injection of immunomodulatory compounds was used as the delivery approach for such agents as IL-12, ${ }^{32}$ or viral vectors encoding cytokine genes IFN- $\gamma^{33}$ or IL-12. ${ }^{34}$ Therefore, to improve the efficacy of IL-18, we chose the intratumoral injection as a delivery method.
In the current study, the syngeneic CT-26WT colorectal cancer model was used to evaluate the anti-tumor effect of engineered IL-18 produced in our laboratory in vivo. Although many studies have described the anti-tumor effect of IL-18 as mentioned above, our study found only a minor ability of native IL-18 to inhibit tumor growth in our animal model after 10 days of treatment with recombinant proteins. This may have been due to the quality of the protein produced in our laboratory, which may lead to the variation in IL-18 quality and activity. However, the engineered IL-18, E6K+T63A, showed a significant antitumor effect as demonstrated in Fig. 1 and Fig. 2. The tumors in the mice treated with E6K+T63A grew slower than those in the mice treated with native protein or E6K IL-18. The mean tumor volume and weight of the E6K and double mutation groups in the CT26-WT colon cancer model were also obviously smaller than in the control group. Compared to the native protein, E6K and E6K+T63A exhibited better effects on tumor regression. These results suggest the combination of E6K and T63A could have a synergetic 
effect on tumors in immunocompetent mice. In addition to tumor progression, this protein also significantly increased the lifespan of this group of mice (Fig. 1B), indicating the strong anti-tumor capability of our engineered IL-18 in an animal model.

Interleukin 18 is a potent inducer of Th1 immune response. ${ }^{1}$ The number of Th1, Th2 and CTL cells in the tumor masses were thus investigated to evaluate the antitumor effect of each type of recombinant IL-18, and these cells could be identified as CD4 $4^{+} \mathrm{IFN}-\gamma^{+}, \mathrm{CD} 4^{+} \mathrm{IL}-4^{+}$and $\mathrm{CD} 8^{+} \mathrm{IFN}-\gamma^{+}$, respectively, in accordance with the role of IFN- $\gamma$ induction. In tumor-bearing mice models, although there was no significant difference in Th2 numbers, the presence of E6K+T63A IL-18 induced significantly greater infiltrations of CD $4^{+} \mathrm{IFN}-\gamma^{+}$T cells and CD ${ }^{+} \mathrm{IFN}_{-} \gamma^{+}$ cells in the tumor masses (Fig. 3,4) compared to the vehicle group supporting a role of our recombinant engineered IL-18 on anti-tumor immunity. This scenario is not surprising, given that IL-18 can recruit T cells to the site, ${ }^{35}$ promote the polarization of Th1 cells, induce the proliferation, enhance the cytotoxicity of $\mathrm{T}$ cells, ${ }^{1}$ and induce the maturation of dendritic cells. ${ }^{36}$

\section{Conclusions}

In summary, the present study confirmed that our engineered IL-18 exhibits anti-tumor capabilities by promoting anti-tumor immunity. Although the native IL-18 produced from our laboratory did not show significant anti-tumor effects according to the tumor volume and survival rate, our engineered IL-18, E6K+T63A, significantly slowed tumor progression and increased the lifespans of tumorbearing mice. These findings may have therapeutic implications, since higher proportions of Th1 and CTL cells were found in the tumor microenvironment of E6K+T63A IL-18-treated mice compared to E6K and native IL-18. Before this technology can be moved into clinical trials, further investigation is needed to elucidate the toxicity and biology of the novel IL-18 type.

\section{ORCID iDs}

Jirakrit Saetang (D) https://orcid.org/0000-0003-2769-8149

Pennapa Chonpathompikunlert

(D) https://orcid.org/0000-0003-2764-0465

Somporn Sretrirutchai (D) https://orcid.org/0000-0002-1033-4544 Niran Roongsawang (D) https://orcid.org/0000-0002-2114-5052

Kanita Kayasut (D) https://orcid.org/0000-0001-7010-6626 Supayang Piyawan Voravuthikunchai

(1) https://orcid.org/0000-0002-1682-2880

Wanida Sukketsiri (D) https://orcid.org/0000-0003-0836-1487

Varomyalin Tipmanee (D) https://orcid.org/0000-0001-6017-7519

Surasak Sangkhathat (D) https://orcid.org/0000-0003-3622-3233

\section{References}

1. Nakanishi K, Yoshimoto T, Tsutsui H, Okamura H. Interleukin-18 is a unique cytokine that stimulates both Th1 and Th2 responses depending on its cytokine milieu. Cytokine Growth Factor Rev. 2001; 12(1):53-72.
2. Okamura $\mathrm{H}$, Tsutsi $\mathrm{H}$, Komatsu $\mathrm{T}$, et al. Cloning of a new cytokine that induces IFN-gamma production by T cells. Nature. 1995;378(6552): 88-91.

3. Arend WP, Palmer G, Gabay C. IL-1, IL-18, and IL-33 families of cytokines. Immunol Rev. 2008;223:20-38.

4. Robinson D, Shibuya K, Mui A, et al. IGIF does not drive Th1 development but synergizes with IL-12 for interferon-gamma production and activates IRAK and NFkappaB. Immunity. 1997;7(4):571-581.

5. Mailliard RB, Alber SM, Shen H, et al. IL-18-induced CD83+CCR7+ NK helper cells. J Exp Med. 2005;202(7):941-953.

6. Li J, Qiu G, Fang B, Dai X, Cai J. Deficiency of IL-18 aggravates esophageal carcinoma through inhibiting IFN- $\gamma$ production by $\mathrm{CD} 8+\mathrm{T}$ cells and NK cells. Inflammation. 2018;41(2):667-676.

7. Xing Y, Tian Y, Kurosawa T, et al. Inhibition of blood vessel formation in tumors by IL-18-polarized M1 macrophages. Genes Cells. 2016;21(3): 287-295.

8. Du G, Ye L, Zhang G, Dong Q, Liu K, Tian J. Human IL18-IL2 fusion protein as a potential antitumor reagent by enhancing NK cell cytotoxicity and IFN- $\gamma$ production. J Cancer Res Clin Oncol. 2012;138(10):1727-1736.

9. Robertson MJ, Kirkwood JM, Logan TF, et al. A dose-escalation study of recombinant human interleukin-18 using two different schedules of administration in patients with cancer. Clin Cancer Res. 2008;14(11):3462-3469.

10. Robertson MJ, Mier JW, Logan T, et al. Clinical and biological effects of recombinant human interleukin-18 administered by intravenous infusion to patients with advanced cancer. Clin Cancer Res. 2006; 12(14 Pt 1):4265-4273.

11. Hashimoto W, Osaki T, Okamura H, et al. Differential antitumor effects of administration of recombinant IL-18 or recombinant IL-12 are mediated primarily by Fas-Fas ligand-and perforin-induced tumor apoptosis, respectively. J Immunol. 1999;163(2):583-589.

12. Micallef MJ, Yoshida K, Kawai S, et al. In vivo antitumor effects of murine interferon-gamma-inducing factor/interleukin-18 in mice bearing syngeneic Meth A sarcoma malignant ascites. Cancer Immunol Immunother. 1997;43(6):361-367.

13. Subleski JJ, Hall VL, Back TC, Ortaldo JR, Wiltrout RH. Enhanced antitumor response by divergent modulation of natural killer and natural killer T cells in the liver. Cancer Res. 2006;66(22):11005-11012.

14. Okamoto T, Yamada N, Tsujimura T, et al. Inhibition by interleukin-18 of the growth of Dunn osteosarcoma cells. J Interferon Cytokine Res. 2004;24(3):161-167.

15. Cao R, Farnebo J, Kurimoto M, Cao Y. Interleukin-18 acts as an angiogenesis and tumor suppressor. FASEB J. 1999;13(15):2195-2202.

16. Redlinger RE, Mailliard RB, Lotze MT, Barksdale EM. Synergistic interleukin-18 and low-dose interleukin-2 promote regression of established murine neuroblastoma in vivo. J Pediatr Surg. 2003;38(3):301-307.

17. Fan $X$, Ye M, Xue $B, K e Y$, Wong $C K$, Xie Y. Human dendritic cells engineered to secrete interleukin-18 activate MAGE-A3-specific cytotoxic T lymphocytes in vitro. Immunol Invest. 2012;41(5):469-483.

18. Saito T, Takayama T, Osaki T, et al. Combined mobilization and stimulation of tumor-infiltrating dendritic cells and natural killer cells with Flt3 ligand and IL-18 in vivo induces systemic antitumor immunity. Cancer Sci. 2008;99(10):2028-2036.

19. Hu B, Ren J, Luo Y, et al. Augmentation of antitumor immunity by human and mouse CAR T cells secreting IL-18. Cell Rep. 2017;20(13): 3025-3033.

20. Chmielewski M, Abken H. CAR T cells releasing IL-18 convert to T-Bethigh FoxO1low effectors that exhibit augmented activity against advanced solid tumors. Cell Rep. 2017;21(11):3205-3219.

21. Wong JL, Muthuswamy R, Bartlett DL, Kalinski P. IL-18-based combinatorial adjuvants promote the intranodal production of CCL19 by NK cells and dendritic cells of cancer patients. Oncoimmunology. 2013;2(9):e26245.

22. Saetang J, Puseenam A, Roongsawang N, Voravuthikunchai SP, Sangkhathat S, Tipmanee V. Immunologic function and molecular insight of recombinant interleukin-18. PloS One. 2016;11(8):e0160321.

23. Kim SH, Azam T, Yoon DY, et al. Site-specific mutations in the mature form of human IL-18 with enhanced biological activity and decreased neutralization by IL-18 binding protein. Proc Natl Acad Sci US A. 2001; 98(6):3304-3309.

24. Swencki-Underwood B, Cunningham MR, Heavner GA, et al. Engineering human IL-18 with increased bioactivity and bioavailability. Cytokine. 2006;34(1-2):114-124. 
25. Tsutsumi N, Kimura T, Arita K, et al. The structural basis for receptor recognition of human interleukin-18. Nat Commun. 2014;5:5340.

26. Yamashita K, Iwasaki T, Tsujimura T, et al. Interleukin-18 inhibits lodging and subsequent growth of human multiple myeloma cells in the bone marrow. Oncol Rep. 2002;9(6):1237-1244.

27. Ohtsuki T, Micallef MJ, Kohno K, Tanimoto T, Ikeda M, Kurimoto M. Interleukin 18 enhances Fas ligand expression and induces apoptosis in Fas-expressing human myelomonocytic KG-1 cells. Anticancer Res. 1997;17(5A):3253-3258.

28. Gołąb J. Interleukin 18, interferon $y$ inducing factor: A novel player in tumour immunotherapy? Cytokine. 2000;12(4):332-338.

29. Liu W, Han B, Sun B, Gao Y, Huang Y, Hu M. Overexpression of interleukin-18 induces growth inhibition, apoptosis and gene expression changes in a human tongue squamous cell carcinoma cell line. J Int Med Res. 2012;40(2):537-544.

30. Nakamura $\mathrm{Y}$, Yamada N, Ohyama H, et al. Effect of interleukin-18 on metastasis of mouse osteosarcoma cells. Cancer Immunol Immunother. 2006;55(9):1151-1158
31. Tse BW-C, Russell PJ, Lochner M, Förster I, Power CA. IL-18 inhibits growth of murine orthotopic prostate carcinomas via both adaptive and innate immune mechanisms. PloS One. 2011;6(9):e24241.

32. van Herpen CM, Looman M, Zonneveld M, et al. Intratumoral administration of recombinant human interleukin 12 in head and neck squamous cell carcinoma patients elicits a T-helper 1 profile in the locoregional lymph nodes. Clin Cancer Res. 2004;10(8):2626-2635.

33. Khorana AA, Rosenblatt JD, Sahasrabudhe DM, et al. A phase I trial of immunotherapy with intratumoral adenovirus-interferon-gamma (TG1041) in patients with malignant melanoma. Cancer Gene Ther. 2003;10(4):251-259.

34. Sangro B, Mazzolini G, Ruiz J, et al. Phase I trial of intratumoral injection of an adenovirus encoding interleukin-12 for advanced digestive tumors. J Clin Oncol. 2004;22(8):1389-1397.

35. Komai-Koma M, Gracie JA, Wei X, et al. Chemoattraction of human T cells by IL-18. J Immunol. 2003;170(2):1084-1090.

36. Gutzmer R, Langer K, Mommert S, Wittmann M, Kapp A, Werfel T. Human dendritic cells express the IL-18R and are chemoattracted to IL-18. J Immunol. 2003;171(12):6363-6371. 